(2)

\section{OPEN ACCESS}

\title{
Pregnancy with complete heart block
}

\author{
Sasmita Swain, ${ }^{1}$ Satyanarayan Routray, ${ }^{2}$ Sandhyarani Behera, \\ Swayamsiddha Mohanty ${ }^{1}$
}

1 Obstetrics and Gynaecology, SCB Medical College \& Hospital, Cuttack, Odisha, India

${ }^{2}$ Cardiology, SCB Medical College \& Hospital, Cuttack, Odisha, India

Correspondence to Dr Satyanarayan Routray; drsnroutray@gmail.com

Accepted 28 October 2021
Check for updates

(c) BMJ Publishing Group Limited 2022. Re-use permitted under CC BY-NC. No commercial re-use. See rights and permissions. Published by BMJ.

To cite: Swain S, Routray $S$, Behera $\mathrm{S}$, et al. BMJ Case Rep 2022;15:e244598. doi:10.1136/bcr-2021244598

\section{SUMMARY}

Pregnancy with complete heart block is rare, its management is not streamlined and requires a multidisciplinary team approach involving the obstetrician, cardiologist, anaesthesiologist and neonatologist. High index of suspicion in a woman with slow heart rate and electrocardiographic examination will ensure the diagnosis of this condition. Such patient can be managed conservatively or may require temporary or permanent pacemaker implantation. We present a 26-year-old primigravida with complete heart block at term pregnancy. She was asymptomatic throughout her pregnancy with pulse rate between 50 and 60 beats per minute. Vaginal delivery was planned under continuous ECG monitoring. Isoprenaline drip and temporary pacemaker were kept stand-by. However, for obstetric reasons caesarean section was performed successfully under spinal anaesthesia without a pacemaker. Method of anaesthesia was planned to keep the haemodynamics stable and drugs causing bradycardia were avoided.

\section{BACKGROUND}

Complete heart block (CHB) is an abnormal heart rhythm in which there is no conduction of electrical impulse through the atrioventricular (AV) node, so that there is complete dissociation of the atria and ventricles. ${ }^{12}$ The escape rhythm can come from lower focus like AV node, bundle of His, bundle branches or Purkinje fibres. ${ }^{3}$ ECG findings of $\mathrm{CHB}$ are (1) regular P-P interval, (2) regular $\mathrm{R}-\mathrm{R}$ interval, (3) lack of an apparent relationship between the P waves and QRS complexes and (4) presence of a greater number of $\mathrm{P}$ waves than QRS complexes. The incidence of $\mathrm{CHB}$ is estimated to be 1 in 15000 to 20000 live birth which may be congenital or acquired. ${ }^{4}$ Whenever encountered in a pregnant woman, $\mathrm{CHB}$ presents a challenge for the obstetrician and calls for a multidisciplinary approach involving the cardiologist, anaesthesiologist and neonatologist.

\section{CASE PRESENTATION}

A 26-year-old primigravida at 38 weeks pregnancy was admitted to Obstetrics and Gynecology Department of SCB Medical College, Cuttack, Odisha, India for safe confinement. She was referred by her obstetrician for delivery under multidisciplinary guidance in view of associated $\mathrm{CHB}$.

Slow pulse rate $(50 / \mathrm{min})$ was detected before her pregnancy, when she consulted a physician for fever in March 2020. ECG revealed CHB with narrow QRS complexes (figure 1). No other organic cardiac problem was detected in echocardiography. She was put on orciprenaline $10 \mathrm{mg}$ two times per day.
Apart from fatigue, tiredness and reeling of head in late pregnancy, she had not experienced any dizziness or syncope. She did not have any palpitations, dyspnoea on exertion or chest pain.

She was conscious, oriented with pulse 50 beats/ min regular and blood pressure of $120 / 76 \mathrm{~mm} \mathrm{Hg}$. Her respiratory rate was $18 / \mathrm{min}$ and chest was bilaterally clear. First heart sound was variable, second heart sound normal and no murmurs were heard. Uterus was term size, relaxed, with cephalic presentation, left occipito anterior (LOA) position, liquor clinically adequate, vertex $5 / 5$ and fetal heart rate $140 \mathrm{bpm}$ regular.

\section{INVESTIGATIONS}

An ultrasound (USG) with Doppler showed a single live fetus of $3 \mathrm{~kg}$ with good biophysical profile. All routine laboratory investigations were normal. Serum $\mathrm{Na}^{+}, \mathrm{K}^{+}, \mathrm{Ca}^{2+}, \mathrm{Mg}^{2+}$ were done to rule out any electrolyte imbalances, and were normal. ECG showed CHB with narrow complex QRS. Echocardiography did not show any organic cardiac problem.

\section{DIFFERENTIAL DIAGNOSIS}

$\mathrm{CHB}$ was differentiated from sinus bradycardia by typical ECG findings.

\section{TREATMENT}

Orciprenaline $10 \mathrm{mg} 8$ hourly was continued but pulse rate did not increase and remained at 50/min. During her hospital stay consultation with cardiologist and anaesthesiologist was done regarding her management during delivery vaginal or lower segment cesarean section (LSCS). As everything was normal, we waited for spontaneous onset of labour. However, on completion of 40 weeks and 2 days patient complained of decreased fetal movement and was very apprehensive. As cervix was not favourable LSCS was planned. The caesarean section was conducted in the morning (routine) hour under spinal anaesthesia in the presence of cardiologist and senior anaesthesiologist. Trans cutaneous pacing pads, isoprenaline drip and temporary pacemaker were kept stand-by. Operation was uneventful.

\section{OUTCOME AND FOLLOW-UP}

A full-term normal female child of $3.1 \mathrm{~kg}$ with APGAR score 9nine was delivered. Both mother and baby were healthy and stable at discharge (figure 2) and 6 weeks follow-up.

\section{DISCUSSION}

Several physiological changes in cardiovascular system occur during pregnancy to meet the 


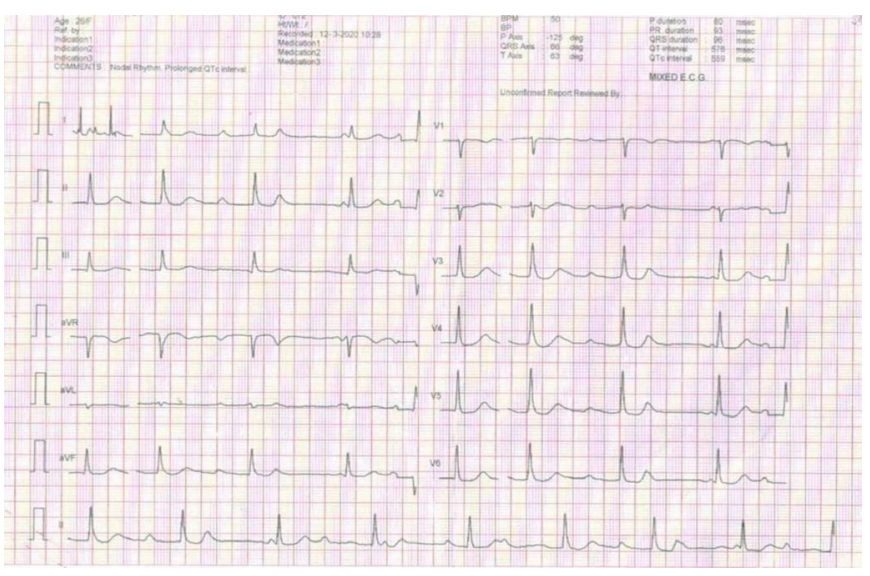

Figure 1 ECG of the patient showing complete heart block, ventricular rate $50 / \mathrm{min}$, recorded during first diagnosis on 12 March 2020.

increased demands. There is rise in circulatory blood volume, stroke volume, heart rate and a fall in systemic vascular resistance during pregnancy. In CHB heart rate fails to increase and may lead to decompensation particularly during intrapartum and postpartum period. There can be distension of all four cardiac chambers, atria being thin walled are affected most. Thaman et al hypothesise that increased atrial wall stress and structural remodelling can result in increased irritability and conduction delay of atrial musculature. This may result in development of new atrial arrhythmia, unmasking of subclinical conduction abnormality and worsening of clinically evident bradyarrhythmias including different grades of heart block. Resolution of such arrhythmia and conduction delay during the postpartum period in certain situation, strongly support the hypothesis. ${ }^{5}$

The finding of $\mathrm{CHB}$ in pregnancy is rare, if present it is usually congenital. In fact, $30 \%$ of the cases of congenital CHB (CCHB) remain undiscovered until adulthood and may therefore present during pregnancy for the first time. ${ }^{1}$ Acquired heart block during pregnancy is very rare and may be due to myocarditis, collagen vascular diseases like systemic lupus erythematous, following infective endocarditis of aortic valve with root abscess or as a complication of cardiac surgery. In acquired heart block, block is distal to AV node, heart rate is usually 40 or less per minute with wide QRS in ECG. They are usually symptomatic in the form of blackout, presyncope or syncope. CCHB can occur as isolated condition or along with other congenital heart disease. Isolated $\mathrm{CCHB}$ is relatively benign, compatible with normal pregnancy, and there may be increase in heart rate with exercise, ${ }^{4}$ atropine ${ }^{5}$ or sympathomimetics like orciprenaline as the block is in AV node in such cases. Some patients with $\mathrm{CCHB}$ may experience dyspnoea, syncope and Stokes-Adams attacks. ${ }^{6}$

Symptoms are common in late months of pregnancy, during labour or immediate post partum. During second stage of labour valsalva during bearing down stimulate vagus nerve and

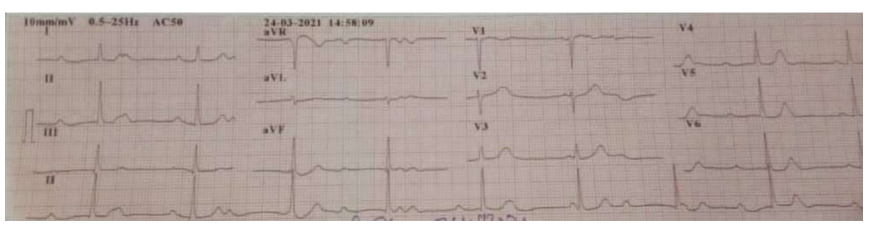

Figure 2 ECG after delivery (complete heart block with ventricular rate $50 / \mathrm{min})$. may cause dangerous bradycardia, asystole and cardiac arrest. Syncope and cardiac arrest have been reported in postpartum period also. Nakashima et al analysed postpartum cardiac events during 63 pregnancies in 36 women. On multivariate analysis family history of $\mathrm{CHB}$ and perinatal ventricular pause was found to be predictors of postpartum cardiac events. ${ }^{7}$ Our patient was almost asymptomatic except undue fatigue, tiredness and reeling of head. She was detected to have CHB before pregnancy, while consulting physician for medical illness.

\section{Pregnancy outcome}

Asymptomatic $\mathrm{CHB}$ without organic heart disease usually have favourable pregnancy outcome. However intrauterine growth restriction (IUGR) and preterm birth has been reported in few patients. $^{8} 9$ Our patient did not have any pregnancy-related complications. In a large series of 21 cases Mandal et al reported oligohydramnious, preterm labour and IUGR in 7\%, 11\% and $14 \%$ of cases respectively. ${ }^{8}$

\section{Delivery options}

There are no definite guidelines for the management of such patients. Vaginal delivery is not contraindicated, caesarean section is reserved for obstetric indications. In the study by Mandal et al, 86\% women had vaginal delivery and 14\% underwent LSCS for obstetric reasons. Patients with CCHB if asymptomatic, with narrow complex in ECG, ventricular rate (heart rate) between 40 and 60 and there is rise in heart rate with exercise or atropine; usually tolerate the pregnancy and delivery without any unfavourable events. ${ }^{10}$

\section{Indications for pacing}

A pacemaker is indicated if there is history of syncope, wide QRS complex, very low heart rate (less than 40/min), QT prolongation, ventricular dysfunction and heart failure. Permanent pacemaker can be implanted at any stage of pregnancy. Short-term temporary pacing may be required during labour and delivery. In earlier days, temporary pacemaker was used routinely in such patients probably to withstand any haemodynamic alterations. It was seen that many of them did not require pacing and the procedure is not without risk. There can be pacemaker-related radiation exposure, bleeding, embolism, right ventricular perforation, infection or pacemaker malfunction. 2018 European Society of Cardiology Guidelines states that isolated CCHB has a favourable outcome during pregnancy especially with narrow QRS. Temporary pacemaker is unnecessary in stable patients but recommended in selected women with symptoms due to bradycardia and syncope. ${ }^{11}$

\section{Approach to monitoring}

Preconceptional counselling-pregnant woman with $\mathrm{CHB}$ and her family members should be counselled for pacemaker implantation, if required during pregnancy.

\section{Antenatal}

Patient should be asked about head reeling, blackout, syncopal attack and shortness of breath on exertion during her antenatal visit. If such symptoms are there cardiological re-evaluation should be done for readjustment of drugs or need of pacemaker.

\section{Intrapartum}

Labour should be monitored and adequate analgesia should be given. Continuous ECG monitoring should be done to detect any life-threatening bradycardia. Instrumental delivery is advocated 
to cut short the second stage of labour and to avoid bearing down by the woman. LSCS is done only for obstetric indications. Isoprenalin infusion should be kept stand-by. Femoral/ jugular venous access may be secured for emergency transvenous temporary pacing, if required.

In the centre, where transcutaneous temporary pacing is available pacing pads should be attached to the chest wall of the woman, so that immediate pacemaker can be given if required. It will avoid the transfer of patient to catheterisation laboratory.

\section{Post partum}

Patient should be monitored in the postpartum period as there is chance of symptomatic bradycardia.

If a temporary pacemaker has been given it has to be removed under the coverage of isoprenalin infusion to avoid the possibility of asystole and cardiac arrest. Such patients may require permanent pacemaker later on and should be followed up.

\section{Contraception}

Caféteria approach with a basket of choices of family planning methods should be offered to the patient as there is no contraindication to any method.

\section{Anaesthetic consideration}

There is no clear guideline as regards the appropriate anaesthesia technique in women with CHB undergoing LSCS. Goal is to maintain the haemodynamic stability, technique and drugs chosen should have minimal effect on heart rate. Spinal, epidural and general anaesthesia, with or without temporary pacemaker has been reported in case reports. ${ }^{12-15}$ Regional anaesthesia is safe in such situation, ${ }^{12}$ as a stable haemodynamic status can be obtained by titrating intravascular volume and phenylephrine infusion guided by continuous invasive monitoring. ${ }^{12}{ }^{13}$ Most authors recommend incremental epidural or low-dose combined spinal and epidural anaesthesia for any instrumental delivery or caesarean section. Our patient underwent caesarean section under spinal anaesthesia without temporary pacemaker support, undercover of oral orciprenaline; with isoprenaline infusion and temporary pacemaker stand-by. We did not encounter any haemodynamic instability probably due to adequate $(750 \mathrm{~mL})$ preloading of intravenous fluid. The baby was $3.1 \mathrm{~kg}$ with normal APGAR score and without any neonatal heart block or structural heart disease.

\section{Learning points}

- Do not forget to palpate and count the pulse. Proper examination gives simple clue to diagnosis and helps preventing future life-threatening adverse events. If pulse rate is less than 60/min do ECG and take opinion of cardiologist.

- Avoid labetolol and other beta blockers like atenolol, metoprolol and so on which may further decrease the heart rate.

- Avoid anaesthetic drugs like prostigmine, fentanyl and suxamethonium which can cause bradycardia and asystole.

- If diagnosed first time in labour or on operation theater (OT) table give intravenous atropine or isoprenaline infusion.

- Plan safe delivery of diagnosed case of complete heart block in a tertiary care hospital where interventional cardiologists are available.

\section{CONCLUSION}

CHB in pregnancy is rare and it is mostly congenital. One of the common investigation ECG can diagnose CHB. Management of such a grave condition need multidisciplinary team approach. Detailed cardiological evaluation with echocardiography (ECHO) and holter is to be done. Resting pulse rate between 40 and 60, narrow QRS complex in ECG and positive chronotropic response to exercise or atropine in an asymptomatic woman predict a benign course, with uneventful labour and delivery. Vaginal delivery is preferred and LSCS is reserved for obstetric indications. Patient and family members are to be properly counselled. Team of doctors should be prepared to tackle any untoward event.

Contributors SS and SR were responsible for conception and design, data acquisition and analysis, drafting of the article and revisiting important intellectual content, gave final approval of the version to be published and agreement to accuracy of data and integrity of the article. SB and SM performed study conception and design, data acquisition and analysis, drafting of the article, gave final approval of the version to be published and agreement to accuracy of data and integrity of the article.

Funding The authors have not declared a specific grant for this research from any funding agency in the public, commercial or not-for-profit sectors.

Competing interests None declared.

Patient consent for publication Consent obtained directly from patient(s).

Provenance and peer review Not commissioned; externally peer reviewed.

Open access This is an open access article distributed in accordance with the Creative Commons Attribution Non Commercial (CC BY-NC 4.0) license, which permits others to distribute, remix, adapt, build upon this work non-commercially, and license their derivative works on different terms, provided the original work is properly cited and the use is non-commercial. See: http://creativecommons.org/ licenses/by-nc/4.0/.

Case reports provide a valuable learning resource for the scientific community and can indicate areas of interest for future research. They should not be used in isolation to guide treatment choices or public health policy.

\section{REFERENCES}

1 Reid JM, Coleman EN, Doig W. Complete congenital heart block. Report of 35 cases. Br Heart J 1982;48:236-9

2 Dalvi BV, Chaudhuri A, Kulkarni HL, et al. Therapeutic guidelines for congenital complete heart block presenting in pregnancy. Obstet Gynecol 1992;79:802-4.

3 Hidaka NChiba Y, Kurita T, Kurita T, et al. Is intrapartum temporary pacing required for women with complete atrioventricular block? an analysis of seven cases. BJOG 2006;113:605-7

4 Michaelsson M, Allen Engle M. Congenital complete heart block: an international study of the natural history. Cardiovasc Clinics 1972;4:85-101.

5 Thaman R, Curtis S, Faganello G, et al. Cardiac outcome of pregnancy in women with a pacemaker and women with untreated atrioventricular conduction block. Europace 2011;13:859-63.

6 Kumar AU, Sripriya R, Parthasarathy $S$, et al. Congenital complete heart block and spinal anaesthesia for caesarean section. Indian J Anaesth 2012;56:72-4.

7 Nakashima A, Miyoshi T, Aoki-Kamiya C, et al. Predicting postpartum cardiac events in pregnant women with complete atrioventricular block. J Cardiol 2019;74:347-52.

8 Mandal Det al. Complete heart block and pregnancy outcome: an analysis from eastern India. SOJGOW 2015;1:1-5.

9 Suri V, Keepanasseril A, Aggarwal N, et al. Maternal complete heart block in pregnancy: analysis of four cases and review of management. J Obstet Gynaecol Res 2009;35:434-7.

10 Hidaka NChiba Y, Fukushima K, Fukushima K, et al. Pregnant women with complete atrioventricular block: perinatal risks and review of management. Pacing Clin Electrophysiol 2011;34:1161-76.

11 Regitz-Zagrosek V, Roos-Hesselink JW, Bauersachs J, et al. 2018 ESC guidelines for the management of cardiovascular diseases during pregnancy. Eur Heart J 2018:39:3165-241.

12 Langesaeter E, Dragsund M, Rosseland LA. Regional anaesthesia for a caesarean section in women with cardiac disease: a prospective study. Acta Anaesthesio/ Scand 2010;54:46-54.

13 Modi MP, Butala B, Shah VR. Anaesthetic management of an unusual case of complete heart block for LSCS. Indian J Anaesth 2006;SO:43-4. 
14 Sundararaman L, Hochman Cohn J, Ranasinghe JS. Complete heart block in pregnancy: case report, analysis, and review of anesthetic management. J Clin Anesth 2016;33:58-61.
15 Aratake S, Yasuda A, Sawamura S. Cesarean section under spinal anesthesia in acquired complete atrioventricular block without a pacemaker: a case report. Clin Case Rep 2019;7:1663-6.

Copyright 2022 BMJ Publishing Group. All rights reserved. For permission to reuse any of this content visit https://www.bmj.com/company/products-services/rights-and-licensing/permissions/

BMJ Case Report Fellows may re-use this article for personal use and teaching without any further permission.

Become a Fellow of BMJ Case Reports today and you can:

- Submit as many cases as you like

- Enjoy fast sympathetic peer review and rapid publication of accepted articles

- Access all the published articles

Re-use any of the published material for personal use and teaching without further permission

Customer Service

If you have any further queries about your subscription, please contact our customer services team on +44 (0) 2071111105 or via email at support@bmj.com.

Visit casereports.bmj.com for more articles like this and to become a Fellow 